\title{
SISTEM PAKAR MUTU BUDIDAYA TANAMAN TEMBAKAU MADURA MENGGUNAKAN METODE FUZZY AHP
}

\author{
Aditya Bagus Wirawan ${ }^{1}$, Ariadi Retno Tri Hayati Ririd ${ }^{2}$, Hendra Pradibta ${ }^{3}$ \\ Program Studi Teknik Informatika, Jurusan Teknologi Informasi, Politeknik Negeri Malang ${ }^{1}$ \\ ${ }^{1}$ adityabaguswirawan.abw@gmail.com, ${ }^{2}$ faniri4education@gmail.com, ${ }^{3}$ hendra_pradibta@ polinema.ac.id
}

\begin{abstract}
Abstrak
Tembakau Madura merupakan salah satu tembakau local aromatis yang berada di pulau Madura. Sebagai sumber aroma, tembakau Madura dapat disubsitusikan dengan tembakau lain meskipun dalam jumlah terbatas. Berdasarkan kegunaanya, tembakau Madura dirajang untuk bahan baku dan sebagian kecil untuk susur. Dalam sektor budidaya, penanaman tembakau mempunyai caranya sendiri untuk melakukan pembudidayaan yang baik dan benar, teknik dari pembudidayaan tersebut dilakukan dari pembenihan sampai pada pengolahan hasil dari tanaman tembakau dengan ketentuan kemurnian dari tembakau tersebut yang terjaga. Sehingga tembakau dengan varietas yang hanya berkualitas baik yang dapat diterima oleh pihak gudang, maka diperlukan sebuah penelitian untuk membuat sistem yang berguna untuk mengetahui bagaimana melakukan pembudidayaan tanaman tembakau Madura dengan menggunakan metode penelitian fuzzy AHP. Penerapan metode ini dilakukan agar dapat membantu pihak yang terkait dengan tembakau mengetahui bagaimana membudidayaan tembakau yang benar sehingga mempunyai nilai jual yang tinggi. Dari penerapan metode tersebut dapat diketahui jenis jenis tembakau yang berkualitas baik, sehingga dapat membuat penjualan tembakau terhadap gudang dapat diterima.
\end{abstract}

Kata Kunci : budidaya tembakau, mutu tembakau, Fuzzy Analytic Hierarchy Process (F-AHP), pabrikan dan gudang tembakau di Kabupaten Pamekasan.

\section{Pendahuluan}

Tembakau Madura merupakan salah satu tembakau local aromatis yang dikembangkan di pulau Madura. Berdasarkan kegunaanya, tembakau Madura dirajang untuk bahan baku dan sebagian kecil untuk susur. Ciri utama tembakau rajangan untuk rokok, pangkal daunnya duduk dan lembaran daun lebih tipis dari tembakau untuk susur. Areal pengembangannya berpusat didua kabupaten, yaitu Pamekasan dan Sumenep. Pada saat ini tembakau Madura yang berkembang sebagai bahan baku rokok adalah varietas - varietas yang telah dilepas oleh Balitas (Balai Penelitian Tembakau dan Tanaman Serat) yaitu Prancak 95.

Sebagai sumber aroma (Ahmad,1993) tembakau Madura dapat disubsitusikan dengan tembakau lain meskipun dalam jumlah terbatas. Oleh karena itu tembakau rajangan Madura harus tersedia setiap saat. Jika kebutuhan tidak terpenuhi, kekurangan dapat diganti tembakau lain misalnya tembakau waleri, mranggen, paiton atau tembakau Madura hasil panen sebelumnya. Hal ini dimungkinkan karena tembakau hasil panen tidak langsung dipakai tetapi memerlukan penyimpanan 23 tahun sebelum digunakan.

Tembakau dengan varietas yang berkualitas baik yang bisa masuk dan di terima pihak gudang, setiap gudang mempunyai kualitasnya sendirisendiri untuk dapat mengambil hasil tembakau dari petani, maka dari itu petani tembakau harus mengetahui teknis pembudidayaan tembakau Madura yang benar. Dan bagi pihak gudang untuk mengetahui kualitas yang di jual petani baik dapat di lakukan dengan penyortiran tembakau yang dilakukan oleh Grader (orang yang menyeleksi kualitas tembakau) dalam keadaan gudang yang ada di kabupaten Pamekasan saat ini, seorang grader ini sebagian besar adalah keluarga atau pemilik dari gudang karena pihak gudang mempunyai rasa ketidakpercayaan terhadap orang lain untuk dijadikan seorang grader.

Dari penjelasan di atas, maka akan dibuat sebuah sistem pakar mutu budidaya tanaman tembakau Madura menggunakan metode Fuzzy AHP dengan tujuan dapat membantu pihak gudang meringankan beban grader untuk menentukan mutu tembakau yang baik sesuai dengan kriteria-kriteria dari hasil tembakau yang di hasilkan, baik dari bentuk, warna, aroma, rasa samapai pada kemurnian tembakau dan pada sistem ini dapat membantu petani untuk mengetahui bagaimana membudidayakan tanaman tembakau yang mempunyai mutu bagus sehingga dapat di terima oleh gudang. 


\section{Landasan Teori}

\subsection{Tembakau}

Tembakau Madura dibutuhkan oleh industry rokok kretek karena mutunya yang khas, yaitu rasa dan aromanya yang gurih. Siahaan (1995) menyatakan pada tahun 1995 kebutuhan tembakau Madura sebanyak 23.085 ton, sedangkan yang tersedia dari panen tahun 1994 hanya 15.939 ton karena produktivitas tembakau Madura rendah. Sampai dengan tahun 1989 produktivitas rata-rata 240-450 kg/ha (Suwarso dan Mukani, 1989), beberapa tahun berikutnya meningkat menjadi 400$550 \mathrm{~kg} / \mathrm{ha}$. Data kepentingan kriteria budidaya dan kualitas mutu didapatkan dari dinas kehutanan dan perkebunan kabupaten Pamekasan

Tabel 2.1 Kepentingan kriteria budidaya tanaman tembakau

\begin{tabular}{|c|c|}
\hline Nama Kriteria & Kepentingan \\
\hline Kualitas Mutu & $\begin{array}{l}5 \text { kali lebih penting dari teknik } \\
\text { pembibitan } \\
4 \text { kali lebih penting dari teknik } \\
\text { pengolahan hasil } \\
3 \text { kali lebih penting dari teknik } \\
\text { penanaman } \\
2 \text { kali lebih penting dati varietas } \\
\text { dan benih }\end{array}$ \\
\hline $\begin{array}{l}\text { Varietas dan } \\
\text { Benih }\end{array}$ & $\begin{array}{l}4 \text { kali lebih penting dari teknik } \\
\text { pembibitan } \\
3 \text { kali lebih penting dari teknik } \\
\text { pengolahan hasil } \\
2 \text { kali lebih penting dari teknik } \\
\text { penanaman }\end{array}$ \\
\hline $\begin{array}{l}\text { Teknik } \\
\text { penanaman }\end{array}$ & $\begin{array}{l}3 \text { kali lebih penting dari teknik } \\
\text { pembibitan } \\
2 \text { kali lebih penting dari teknik } \\
\text { pengolahan hasil }\end{array}$ \\
\hline $\begin{array}{l}\text { Teknik } \\
\text { pengolahan } \\
\text { hasil }\end{array}$ & $\begin{array}{l}2 \text { kali lebih penting dari teknik } \\
\text { pembibitan }\end{array}$ \\
\hline $\begin{array}{l}\text { Teknik } \\
\text { pembibitan }\end{array}$ & - \\
\hline
\end{tabular}

Sumber : Dinas Kehutana dan Perkebunan Kabupaten Pamekasan

\subsection{Sistem Pakar}

Sistem pakar adalah sistem berbasis computer yang menggunakan pengetahuan, fakta, dan teknik penalaran dalam memecahkan masalah yang biasanya hanya dapat dipecahkan oleh seorang pakar dalam bidang tersebut (Martin dan Oxman, 1988).

\subsection{Fuzzy Analytical Hierarchy Process (FAHP)}

Fuzzy AHP adalah salah satu metode perankingan. FAHP merupakan gabungan metode AHP dengan pendekatan konsep fuzzy (Raharjo dkk, 2002). F-AHP menutupi kelemahan yang terdapat pada AHP yaitu permasalahan terhadap kriteria yang memiliki sifat subjektif lebih banyak. Ketidakpastian bilangan direpresentasikan dengan urutan skala. Untuk menentukan derajat keanggotaan pada F-AHP digunakan aturan fungsi dalam bentuk bilangan fuzzy segitiga atau Triangular Fuzzy Number (TFN) yang disusun berdasarkan himpunan linguistik. Jadi, bilangan pada tingkat intensitas kepentingan pada AHP ditransformasikan ke himpunan skala TFN.

Tabel 2.2 Fungsi Keanggotaan Skala Linguistik

\begin{tabular}{|c|l|l|}
\hline $\begin{array}{c}\text { Skala } \\
\text { Fuzzy }\end{array}$ & \multicolumn{1}{|c|}{ Keterangan } & $\begin{array}{c}\text { Skala Bilangan } \\
\text { Fuzzy }\end{array}$ \\
\hline 1 & Sama Penting & $(1,1,3)$ \\
\hline 3 & Sedikit Lebih Penting & $(1,3,5)$ \\
\hline 5 & Jelas Lebih Penting & $(3,5,7)$ \\
\hline 7 & Sangat Jelas Lebih Penting & $(5,7,9)$ \\
\hline 9 & Mutlak Lebih Penting & $(7,9,9)$ \\
\hline
\end{tabular}

Tahapan fungsi triangular $\mu_{\tilde{A}}(x)$ dengan pendefinisian sebagai berikut

$$
\mu_{\tilde{\mathrm{A}}}(x)=\left\{\begin{array}{c}
0, x<a_{1} \\
\frac{x-a_{1}}{a_{m-a_{1}}}, a_{1} \leq x \leq a_{m} \\
\frac{a_{u}-x}{a_{u}-a_{m}}, a_{m} \leq x \leq a_{u} \\
0, x>a_{u}
\end{array}\right\}
$$

Operasi aritmetika pada TFN $\tilde{\mathrm{A}}_{1}=\left(L_{1}, M_{1}, U_{1}\right)$ dan $\tilde{\mathrm{A}}_{2}=\left(L_{2}, M_{2}, U_{2}\right)$ adalah:

$$
\begin{array}{ll}
\tilde{\mathrm{A}}_{1} \oplus \tilde{\mathrm{A}}_{2} & =\left(L_{1}+L_{2}, M_{1}+M_{2}, U_{1}+U_{2}\right) \\
\tilde{\mathrm{A}}_{1} \oplus \tilde{\mathrm{A}}_{2} & =\left(L_{1} L_{2}, M_{1} M_{2}, U_{1} U_{2}\right) \\
\tilde{\mathrm{A}}_{1}-\tilde{\mathrm{A}}_{2} & =\left(L_{1}-U_{2}, M_{1}-M_{2}, U_{1}+L_{2}\right) \\
\tilde{\mathrm{A}}_{1} / \tilde{\mathrm{A}}_{2} & =\left(L_{1} / U_{2}, M_{1} / M_{2}, U_{1}+L_{2}\right) \\
\tilde{\mathrm{A}}_{1}^{-1} & =\left(1 / L_{1}, 1 / M_{1}, 1 / U_{1}\right)
\end{array}
$$

Untuk mendapatkan bobot kriteria dapat dilakukan dengan cara matrik perbandingan berpasangan disusun diantara kriteriadalam dimensi hirarki berdasarkan skala fuzzy

$$
\tilde{\mathrm{A}}=\left[\begin{array}{cccc}
1 & \tilde{\mathrm{a}}_{12} & \ldots & \tilde{\mathrm{a}}_{1 n} \\
\tilde{\mathrm{a}}_{21} & 1 & \cdots & \tilde{\mathrm{a}}_{2 n} \\
, & , & , & \\
\tilde{\mathrm{a}}_{n 1} & \tilde{\mathrm{a}}_{n 2} & \ldots & 1
\end{array}\right]
$$

Dimana

$$
\tilde{a}_{21}=\left\{\begin{array}{c}
\tilde{1}, \tilde{3}, \breve{5}, \tilde{7}, \widetilde{9} \\
\widetilde{1^{-1}}, \widetilde{3^{-1}}, \frac{1}{5^{-1}}, \widetilde{7^{-1}}, \widetilde{9^{-1}}
\end{array}\right.
$$

Selanjutnya dengan Mendefinisikan rata-rata geometris fuzzy dan bobot fuzzy setiap kriteria dengan rata-rata.

$$
\tilde{r}_{1}=\tilde{a}_{i 1} \oplus \tilde{a}_{i 2} \oplus \ldots \ldots \oplus \tilde{a}_{i n}
$$


Tabel 4.3 Tabel nilai sintesis fuzzy

\begin{tabular}{|l|r|r|r|}
\hline & 1 & $\mathrm{~m}$ & $\mathrm{u}$ \\
\hline $\begin{array}{l}\text { Varietas dan } \\
\text { benih }\end{array}$ & 0.00616541 & & 4.49771379 \\
& 7 & 0.09994087 & 2 \\
Pembibitan & $1.0356 \mathrm{E}-07$ & $7.83389 \mathrm{E}-$ & $5.39624 \mathrm{E}-$ \\
& & 07 & 05 \\
\hline Penanaman & $1.7975 \mathrm{E}-05$ & 0.00057109 & 0.03084851 \\
\hline & $7.24917 \mathrm{E}-$ & $1.94249 \mathrm{E}-$ & 0.00158649 \\
Hasil & 07 & 05 & 5 \\
\hline & 0.03082708 & 0.89946783 & 22.4885689 \\
Mutu & 5 & 1 & 6 \\
\hline & 0.03701130 & & 27.0187717 \\
Jumlah & 5 & 1 & 3 \\
\hline
\end{tabular}

$$
\widetilde{W}_{1}=\tilde{r}_{i} \oplus\left(\tilde{r}_{1} \oplus \ldots \ldots \tilde{r}_{n}\right)^{-1}
$$

Dimana $\tilde{a}_{i n}$ adalah nilai perbandingan fuzzy dari kriteria i ke n, $\tilde{r}_{i}$ adalah rata-rata geometris dari nilai perbandingan fuzzy kriteria i terhadapa setiap kriteria dan i $\widetilde{W}$ adalah bobot fuzzy dari kriteria ke-i.

$$
\begin{aligned}
\mathrm{BN}_{1}= & \frac{l_{1}+\left(\left(m_{1}-l_{1}\right)+\left(u_{1}-l_{1}\right)\right)}{3} \\
\mathrm{BN}_{1}= & 0.006165417+((0.09994087- \\
& 0.006165417)+(4.497713792- \\
& 0.006165417)) / 3 \\
= & 9.071745758
\end{aligned}
$$

Dihitung sampai banyaknya kriteria dan di hitung jumlah keseluruhan nilai bobot kriteria, sehingga hasilnya;

$$
\begin{aligned}
& \mathrm{K} 1=1.534606693 \\
& \mathrm{~K} 2=1.82831 \mathrm{E}-05 \\
& \mathrm{~K} 3=0.010479194 \\
& \mathrm{~K} 4=0.000535548 \\
& \mathrm{~K} 5=7.806287959 \\
& \text { Jumlah }=9.351927677
\end{aligned}
$$

Mencari bobot dari kriteria dengan rumus sebagai berikut ;

$$
\begin{aligned}
\text { Bobot K1 } & =\frac{B N_{n}}{j m l B N} \\
& =\frac{1.534606693}{9.351927677} \times 100 \\
& =16.40952268
\end{aligned}
$$

Dicari sampai pada kriteria ke 5 dan di jumlah keseluruhan bobotnya menghasilkan nilai 100, dilakukan hal yang sama untuk subkriteria untuk pencarian bobotnya, sehingga dapat nilai bobot relatif untuk subkriteria dan bobot absolut untuk relasi antara kriteria dan subkriteria.

\section{Analisis dan Perancangan \\ 3.1 Analisis Sistem \\ a) Usecase}

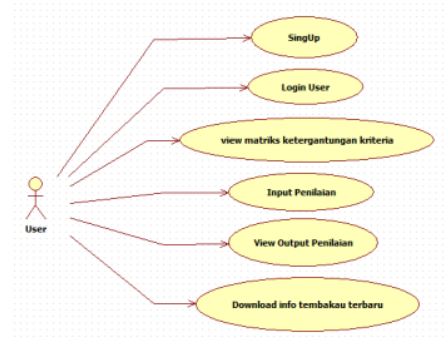

Gambar 3.1 Gambar usecase user

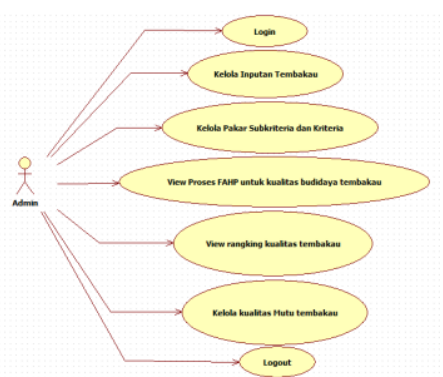

Gambar 3.2 Gambar usecase admin

Untuk membangun sebuah sistem diperlukannya sebuah perancangan. Perancangan seperti use case diatas ini terdapat dua actor yaitu user dan admin. User memiliki akses untuk melakukan penilaian budidaya tanaman tembakau dan melihat mutu budidaya tanaman tembakau. Admin memiliki akses untuk melakukan pengelolaan kepentingan kriteria dan sub kriteria, kelola inputan budidaya, kelola kualitas mutu dan hasil mutu budidaya tembakau.

b) Proses penentuan mutu budidaya tanaman tembakau

Contoh kasus petani menginputkan data dari budidaya tembakau yang sudah dilakukan dengan ketentuan.

\begin{tabular}{|l|c|}
\hline \multicolumn{1}{|c|}{ Keyakinan } & Nilai Bobot \\
\hline Sangat Baik & 5 \\
\hline Baik & 4 \\
\hline Cukup & 3 \\
\hline Kurang & 2 \\
\hline Sangat Kurang & 1 \\
\hline
\end{tabular}

Dengan contoh kasus tersebut bisa diketahui dengan perhitungan seperti di bawah ini:

- Bobot Varietas tembakau

= Nilai Varietas $\mathrm{x}$ Bobot Varietas

$=5 \times 0.715383723$

$=3.576919$

- Benih Tembakau

$=$ Nilai Benih $x$ Bobot Benih

$=4 \times 15.69413895$

$=62.77656$ 
Dilakukan sampai pada subkriteria terakhir yaitu ketuaan sehingga di dapatkan hasil sebagai berikut :

\begin{tabular}{|c|c|c|c|c|}
\hline Kriteria & Bobot & Subkriteria & $\begin{array}{c}\text { Bobot } \\
\text { Subkriteria }\end{array}$ & $\begin{array}{l}\text { Bobot } \\
\text { Relatif }\end{array}$ \\
\hline \multirow{2}{*}{$\begin{array}{l}\text { Varietas } \\
\text { dan Benih }\end{array}$} & \multirow{2}{*}{16.41} & $\begin{array}{l}\text { Varietas } \\
\text { Tembakau }\end{array}$ & 4.359564486 & 0.715383723 \\
\hline & & \begin{tabular}{|l} 
Benih \\
Tembakau
\end{tabular} & 95.64043551 & 15.69413895 \\
\hline \multirow{7}{*}{$\begin{array}{l}\text { Teknik } \\
\text { Pembibitan }\end{array}$} & \multirow{7}{*}{0.0002} & $\begin{array}{l}\text { Lokasi } \\
\text { pembibitan }\end{array}$ & 63.69173675 & 0.000124518 \\
\hline & & $\begin{array}{l}\text { Pengolahan } \\
\text { tanah untuk } \\
\text { bedegan } \\
\end{array}$ & 0.000384971 & 7.52622E-10 \\
\hline & & \begin{tabular}{|l|} 
Penaburan \\
benih
\end{tabular} & 0.00320826 & 6.27218E-09 \\
\hline & & \begin{tabular}{|l|}
$\begin{array}{l}\text { Pengendalian } \\
\text { hama penyakit }\end{array}$ \\
\end{tabular} & 0.000356743 & $6.97436 \mathrm{E}-10$ \\
\hline & & Melatih bibit & 0.240618927 & 4.70413E-07 \\
\hline & & \begin{tabular}{|l|}
$\begin{array}{l}\text { Pencabutan } \\
\text { bibit }\end{array}$ \\
\end{tabular} & 0.562597808 & $1.09988 \mathrm{E}-06$ \\
\hline & & \begin{tabular}{|l|} 
Bibit yang \\
diharapkan
\end{tabular} & 35.50109654 & $6.9405 \mathrm{E}-05$ \\
\hline \multirow{11}{*}{$\begin{array}{l}\text { Teknik } \\
\text { Penanaman }\end{array}$} & \multirow{11}{*}{0.112} & \begin{tabular}{|l|} 
Pengolahan \\
Tanah \\
\end{tabular} & 88.88980275 & 0.099604439 \\
\hline & & Jarak Tanam & 1.097404953 & 0.001229684 \\
\hline & & Penanaman & 0.000645075 & 7.22831E-07 \\
\hline & & \begin{tabular}{|l} 
Cara \\
Menanam \\
Bibit \\
\end{tabular} & 0.013546635 & $1.51795 \mathrm{E}-05$ \\
\hline & & Penyulaman & 4.91487E-08 & 5.50731E-11 \\
\hline & & Pemupukan & $3.07178 \mathrm{E}-05$ & 3.44204E-08 \\
\hline & & \begin{tabular}{|l|} 
Waktu dan \\
Cara \\
Pemberian \\
Pupuk \\
\end{tabular} & $1.22871 \mathrm{E}-06$ & $1.37682 \mathrm{E}-09$ \\
\hline & & Pengairan & 0.121923965 & 0.00013662 \\
\hline & & \begin{tabular}{|l|} 
Dangir dan \\
Bumbun \\
\end{tabular} & $2.3405 \mathrm{E}-09$ & 2.62262E-12 \\
\hline & & Pemangkasan & 9.876644627 & 0.01106716 \\
\hline & & $\begin{array}{l}\text { Cara Panen } \\
\text { Tembakau }\end{array}$ & $1.11461 \mathrm{E}-10$ & $1.24897 \mathrm{E}-13$ \\
\hline \multirow{5}{*}{$\begin{array}{l}\text { Teknik } \\
\text { Pengolahan } \\
\text { Hasil }\end{array}$} & \multirow{5}{*}{0.0057} & Sortasi & 90.62398014 & 0.005189681 \\
\hline & & Perajangan & 6.484239158 & 0.000371327 \\
\hline & & Penjemuran & 2.165614889 & 0.000124016 \\
\hline & & Pembungkusan & 0.726073465 & 4.15794E-05 \\
\hline & & Pemasaran & $9.23497 \mathrm{E}-05$ & 5.2885E-09 \\
\hline \multirow{9}{*}{$\begin{array}{l}\text { Kualitas } \\
\text { Mutu }\end{array}$} & \multirow{9}{*}{83.47} & Warna & 1.23279E-06 & $1.02904 \mathrm{E}-06$ \\
\hline & & Bodi & $3.08604 \mathrm{E}-05$ & $2.576 \mathrm{E}-05$ \\
\hline & & Aroma & 97.96600303 & 81.77467322 \\
\hline & & \begin{tabular}{|l} 
Ukuran \\
Rajangan
\end{tabular} & 9.24994E-05 & $7.72116 \mathrm{E}-05$ \\
\hline & & $\begin{array}{l}\text { Kebersihan } \\
\text { Tembakau } \\
\end{array}$ & 0.000277416 & 0.000231566 \\
\hline & & Posisi Daun & 2.022777196 & 1.688462723 \\
\hline & & Kemurnian & 0.000832167 & 0.000694631 \\
\hline & & Kekeringan & 0.002496419 & 0.002083823 \\
\hline & & Ketuaan & 0.007489175 & 0.006251402 \\
\hline
\end{tabular}

Nilai dari hasil d jumlahkan dan menghasilkan persentase $63.4 \%$ dimana rangking persentase kualitas mutu sebagai berikut:

\begin{tabular}{|l|c|}
\hline Kualitas 1 & $100 \%-80 \%$ \\
\hline Kualitas 2 & $79.9 \%-63.1 \%$ \\
\hline Kualitas 3 & $63 \%-40 \%$ \\
\hline Kualitas 4 & $39.9 \%-20 \%$ \\
\hline
\end{tabular}

Nilai $63.4 \%$ berada pada posisi KW 2

\subsection{Perancangan Sistem}

Pada perancangan proses untuk budidaya akan disajikan ke dalam bentuk rancangan database yang akan diimplementasikan ke dalam sistem

\section{Pengujian dan Sistem}

\subsection{Pengujian Sistem}

Pengujian Sistem dengan diagnosa Pakar

\begin{tabular}{|c|c|c|c|c|}
\hline $\begin{array}{c}\text { Bobot } \\
\text { Absolut }\end{array}$ & $\begin{array}{c}\text { Uji } \\
\text { Coba } \\
1\end{array}$ & Hasil & $\begin{array}{c}\text { Uji } \\
\text { Coba } \\
2\end{array}$ & Hasil \\
\hline 0.715383723 & 5 & 3.576918615 & 5 & 3.576919 \\
\hline 15.69413895 & 5 & 78.47069477 & 4 & 62.77656 \\
\hline 0.000124518 & 5 & 0.00062259 & 3 & 0.000374 \\
\hline $7.52622 \mathrm{E}-10$ & 5 & 3.76311E-09 & 2 & $1.51 \mathrm{E}-09$ \\
\hline 6.27218E-09 & 5 & 3.13609E-08 & 1 & $6.27 \mathrm{E}-09$ \\
\hline 6.97436E-10 & 5 & $3.48718 \mathrm{E}-09$ & 4 & 2.79E-09 \\
\hline 4.70413E-07 & 5 & $2.35206 \mathrm{E}-06$ & 3 & $1.41 \mathrm{E}-06$ \\
\hline 1.09988E-06 & 5 & 5.49942E-06 & 2 & $2.2 \mathrm{E}-06$ \\
\hline 6.9405E-05 & 5 & 0.000347025 & 2 & 0.000139 \\
\hline 0.099604439 & 5 & 0.498022195 & 2 & 0.199209 \\
\hline 0.001229684 & 5 & 0.006148422 & 2 & 0.002459 \\
\hline 7.22831E-07 & 5 & $3.61416 \mathrm{E}-06$ & 2 & $1.45 \mathrm{E}-06$ \\
\hline 1.51795E-05 & 5 & 7.58976E-05 & 4 & $6.07 \mathrm{E}-05$ \\
\hline 5.50731E-11 & 5 & $2.75365 \mathrm{E}-10$ & 2 & $1.1 \mathrm{E}-10$ \\
\hline 3.44204E-08 & 5 & 1.72102E-07 & 4 & $1.38 \mathrm{E}-07$ \\
\hline 1.37682E-09 & 5 & 6.88411E-09 & 3 & 4.13E-09 \\
\hline 0.00013662 & 5 & 0.000683102 & 3 & 0.00041 \\
\hline $2.62262 \mathrm{E}-12$ & 5 & $1.31131 \mathrm{E}-11$ & 3 & $7.87 \mathrm{E}-12$ \\
\hline 0.01106716 & 5 & 0.055335799 & 2 & 0.022134 \\
\hline 1.24897E-13 & 5 & $6.24484 \mathrm{E}-13$ & 1 & $1.25 \mathrm{E}-13$ \\
\hline 0.005189681 & 5 & 0.025948404 & 3 & 0.015569 \\
\hline 0.000371327 & 5 & 0.001856635 & 4 & 0.001485 \\
\hline 0.000124016 & 5 & 0.000620081 & 5 & 0.00062 \\
\hline 4.15794E-05 & 5 & 0.000207897 & 4 & 0.000166 \\
\hline 5.2885E-09 & 5 & $2.64425 \mathrm{E}-08$ & 3 & $1.59 \mathrm{E}-08$ \\
\hline 1.02904E-06 & 5 & 5.14519E-06 & 2 & $2.06 \mathrm{E}-06$ \\
\hline 2.576E-05 & 5 & 0.0001288 & 3 & 7.73E-05 \\
\hline
\end{tabular}




\begin{tabular}{|r|r|r|r|r|}
\hline $\mathbf{8 1 . 7 7 4 6 7 3 2 2}$ & 5 & 408.8733661 & 3 & 245.324 \\
\hline $\mathbf{7 . 7 2 1 1 6 E - 0 5}$ & 5 & 0.000386058 & 5 & 0.000386 \\
\hline $\mathbf{0 . 0 0 0 2 3 1 5 6 6}$ & 5 & 0.001157832 & 3 & 0.000695 \\
\hline $\mathbf{1 . 6 8 8 4 6 2 7 2 3}$ & 5 & 8.442313613 & 3 & 5.065388 \\
\hline $\mathbf{0 . 0 0 0 6 9 4 6 3 1}$ & 5 & 0.003473153 & 3 & 0.002084 \\
\hline $\mathbf{0 . 0 0 2 0 8 3 8 2 3}$ & 5 & 0.010419117 & 2 & 0.004168 \\
\hline $\mathbf{0 . 0 0 6 2 5 1 4 0 2}$ & 5 & 0.03125701 & 4 & 0.025006 \\
\hline Jumlah & & 100 & & 63.40359 \\
\hline
\end{tabular}

\section{Kesimpulan dan Saran}

\subsection{Kesimpulan}

Berdasarkan pembahasan yang telah dilakukan pada bab 1 hingga bab 6, maka dapat disimpulkan bahwa :

a. Aplikasi sistem pakar untuk mutu budidaya tanaman tembakau adalah suatu aplikasi untuk mendiagnosa kualitas mutu budidaya tanaman tembakau berdasarkan pengetahuan dari para pakar.

b. Kriteria, dan subkriteria mutu budidaya dalam sistem bisa diubah - ubah atau bersifat dinamis dan data penilaian tersimpan pada sistem sebagai hasil dari mutu budidaya

c. Perhitungan metode dari sistem pakar dan excel mengeluarkan hasil yang sama.

\subsection{Saran}

Saran yang diberikan untuk pengembangan sistem pakar dalam penelitian ini dibuat menggunakan metode Fuzzy AHP, dan untuk pengembanganya dapat dibandingkan dengan metode lain sehingga mendapatkan hasil yang lebih akurat.

Daftar Pustaka :

Arifin, Zainal,2006, Panduan Teknis Budidaya Tembakau Madura, Pamekasan

Hidayati Anita, Retno Ariadi. Analisa Pengembangan Model Kualitas Berstruktur Hirarki dengan Kustomisasi ISO 9126 untuk Evaluasi Aplikasi Perangkat Lunak B2B. Malang

Kusrini, 2007, Konsep dan Aplikasi Sistem Pakar, Andi Offset, Yogyakarta.

Kusumadewi, Purnomo. 2004. Aplikasi Logika Fuzzy untuk Pendukung Keputusan. Graha Ilmu : Jakarta.

L. Mikhailov, P. Tsvetinov, Evaluation of services using a fuzzy analytic hierarchy process, Applied soft computing Journal, 5, Elsevier, 2004, pp. 23-33.

Pakarti, Andhika Bayu. 2013. Analisis Dan Implementasi Metode Fuzzy AHP dan Topsis Untuk Rekomendasi LPK Pelaksana Proyek Pelatihan (Studi Kasus : Dinas Tenaga Kerja
Kota Samarinda). Jurnal Fakultas Informatika Universitas Telkom.

Meftah, Arif. 2015. Tembakau dan Pasca Panen.[Online] Tersedia pada halaman www.anakagronomy.com/2013/04/panen-danpasca-panen-tembakau.html [13 Februari 2016]

Warintek. 2011. Budidaya Tanaman Tembakau Virginia.[Online] Tersedia pada halaman http://warintek.bantulkab.go.id/web.php?mod $=$ basisdata $\&$ kat $=1 \&$ sub $=2 \&$ file $=32$. Februari 2016] 